\title{
A case series of caesarean myomectomy
}

\section{Shazia Parveen, Nasreen Noor, Iti Madan, Ummay Kulsoom*}

Department of Obstetrics and Gynecology, Jawaharlal Nehru Medical College and Hospital, Aligarh, Uttar Pradesh, India

Received: 17 May 2021

Accepted: 06 August 2021

\section{*Correspondence:}

Dr. Ummay Kulsoom,

E-mail: ummay.kulsoom91@gmail.com

Copyright: ( $)$ the author(s), publisher and licensee Medip Academy. This is an open-access article distributed under the terms of the Creative Commons Attribution Non-Commercial License, which permits unrestricted non-commercial use, distribution, and reproduction in any medium, provided the original work is properly cited.

\begin{abstract}
Uterine fibroids are benign, monoclonal tumors of smooth muscle cells of the myometrium. Most fibroids do not increase in size during pregnancy and are not always removed when encountered during cesarean section. Objective was to see the outcome of patients undergoing cesarean myomectomy. The study design was observational study. All patients undergoing cesarean section with uterine fibroid of size more than $5 \mathrm{~cm}$. In carefully selected patients and with use of intraoperative vasopressin, myomectomy may be safely accomplished at the time of caesarean section by experienced surgeons. cesarean myomectomy is safe and successful if patient selection is done carefully and does not add to any additional post-operative morbidity.
\end{abstract}

Keywords: Uterine fibroid, Caesarean section, Myomectomy

\section{INTRODUCTION}

Uterine fibromyomas affect a large number of women accounting for significant morbidity and health care costs during reproductive age. ${ }^{1-3}$ In pregnant women with increased maternal age there is high incidence of myoma, Hence the possibility to encounter pregnant patients with myomas and the need to treat the associated complications is also rising. ${ }^{4-8}$

Myomas with diameter more than $5 \mathrm{~cm}$ have been associated with preterm labor, premature rupture of membranes and postpartum hemorrhage..$^{9,10}$

Management of myoma during caesarean section remains a controversial issue despite progress in medical and nonsurgical myoma treatment. ${ }^{11}$ Myomectomy is the most common operation performed during cesarean section and accounts for $0.89 \%$ of all cesarean sections. ${ }^{12}$ It's easy to remove pedunculated myomas and hemostasis can be achieved without much difficulty. A patient who undergoes myomectomy during cesarean section will not require a second operation. In addition, cesarean myomectomy also promotes puerperal involution and significantly reduces fibroid related complications that can develop later in life such as menorrhagia, anemia due to heavy bleeding and pain. ${ }^{9}$

Myomectomy during cesarean section was not found in obstetrics literature until recently and it was widely suggested to postpone the myomectomy and perform it later before the next pregnancy. ${ }^{13}$ The most common reason for postponing myomectomy has been prevention of unwanted hysterectomy due to uncontrolled hemorrhage that adds to post-operative morbidity and increased hospital stay. ${ }^{13-15}$

Caesarean myomectomy is still considered a high-risk surgery and with careful case selection and use of vasopressin per operatively, surgical management of uterine myomas during cesarean section may be safe. ${ }^{16}$

\section{CASE SERIES}

\section{Case 1}

A 23-year-old primi patient with 37 weeks 3 days pregnancy, known case of hypothyroidism presented with 
amenorrhea for 9 months. On physical examination she had a term size uterus and the ultrasound abdomen showed an anterior wall intramural myoma of $13 \times 11 \mathrm{~cm}$ dimensions.

She did not have any symptoms related to the myoma such as abnormal uterine bleeding or pain, before or during pregnancy. Her hemoglobin before and after operation was $10.7 \mathrm{~g} \%$ and $8.7 \mathrm{~g} \%$ respectively.

A caesarean myomectomy was planned, and carried out under general anesthesia with delivery of a live female baby followed by removal of myoma. Per operatively, a $25 \times 25 \mathrm{~cm}$ myoma was seen in the anterior wall of uterus (Figure $1 \mathrm{~A}$ and $\mathrm{B}$ ). The histological examination confirmed the diagnosis of myoma.

The patient was discharged 5 days after surgery and the time of discharge, involution of uterus was normal and no post-partum morbidity was faced.

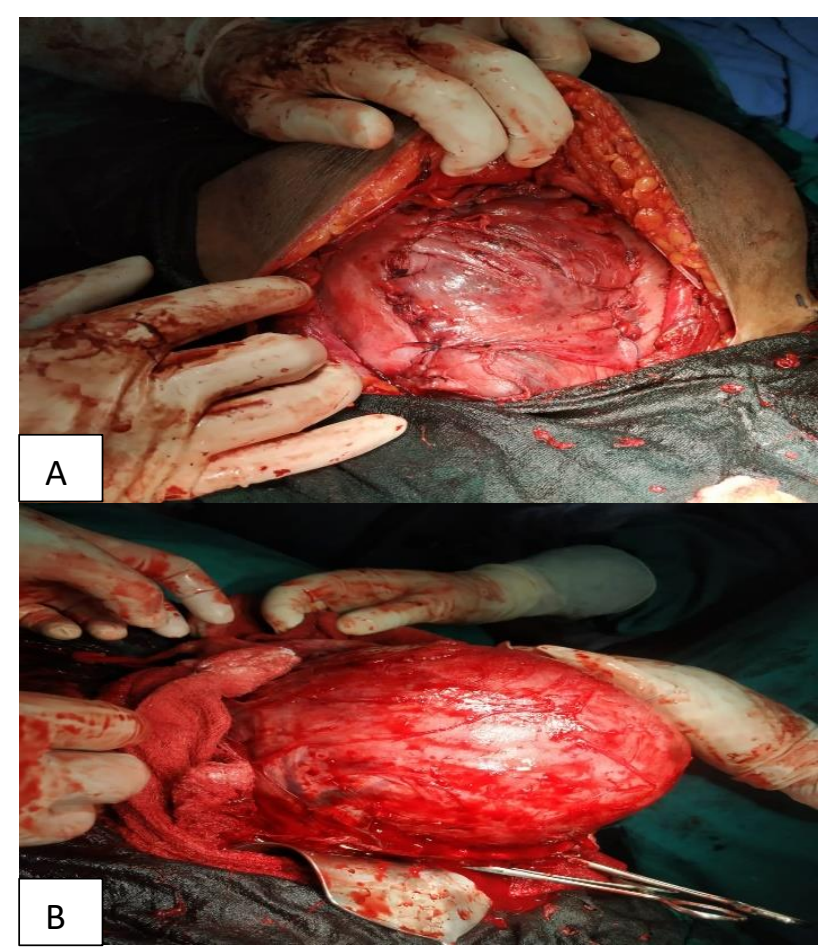

Figure 1 (A and B): A large intramural myoma $(25 \times 25 \mathrm{~cm})$ on the anterior wall of uterus seen during caesarean section.

\section{Case 2}

A-30-years old primigravida presented with 9 months amenorrhea with central placenta previa with bleeding per vaginum for one day. On examination her vitals were stable with a uterus of term size. On local examination active bleeding was present per vaginally. Her second trimester ultrasound revealed an oval intramural myoma of $9.1 \times 6.9 \times 7.6 \mathrm{~cm}$ in the anterior wall of uterus in fundal region.
The patient was taken up for double setup examination followed by caesarean section with delivery of a live male baby and removal of myoma. The inner endometrial layer was not breached. Per op, central placenta previa was present. After removal of placenta and membranes, a large intramural fibroid of approx. 10x9 cm, was noted in the antero- fundal area (Figure 2).

The patient was discharged 3 days after surgery with no post-partum morbidity

\section{Case 3}

A 27 years old gravida 4 with previous three abortions with hypothyroidism with gestational diabetes mellitus with gestational hypertension presented with 9 months amenorrhea. On examination she had a term-sized uterus with stable vitals. Her blood pressure was controlled on oral antihypertensive

She was taken up for caesarean section in view of nonprogress of labour with delivery of a live male baby. Following complete removal of placenta and membranes, a sub serosal fibroid of $8 \times 4 \mathrm{~cm}$ was noted at the left angle of uterus, which was removed successfully. There were no per-operative or postoperative complications and the patient was discharged 3 days after surgery

\section{Case 4}

A 32 years gravida 2 with 1 live issue presented with amenorrhea 9 months with labour pains. On examination her uterus was term size with an ultrasound revealing a sub serosal fibroid of $23 \times 20 \times 25 \mathrm{~cm}$ in the posterior wall of uterus.

Caesarean section was done in view of non-progress of labour with fetal distress followed by removal of myoma under continuous oxytocin infusion. Per operative a large posterior wall intramural myoma was seen measuring around $30 \times 24 \mathrm{~cm}$ with a weight of approximately $3 \mathrm{~kg}$, a small $2 \times 3 \mathrm{~cm}$ fibroid was seen on fundo anterior region of uterus. Bilateral broad ligaments, tubes and ovaries appeared normal. Tissue was sent for histopathology, which later confirmed the diagnosis of myoma. Patient was discharged on day 5 of surgery with no post op complications on follow up.

\section{Case 5}

A total 35 years old primigravida with gestational hypertension presented with 10 months amenorrhea. On examination her uterus was term size with a blood pressure of 142/86 $\mathrm{mmHg}$ controlled on oral medications. Her first trimester ultrasound revealed a sub serosal fibroid of $4 \times 6$ $\mathrm{cm}$ in the posterior wall of uterus.

Patient was taken up for caesarean section in view if fetal distress followed by myomectomy. Per operative, a subserosal myoma of 9x5 cm was noted on right side of 
posterior uterine wall. Tissue was sent for histopathology, which later confirmed the diagnosis of myoma. Patient was discharged on day 4 of surgery without any significant post op complications.

\section{Case 6}

A 25 years old gravida 2 with previous abortion presented with amenorrhea 9 months. On examination she had stable vitals with a uterus of term size. She had a third trimester ultrasound revealing a fibroid of size $7 \times 5 \mathrm{~cm}$ in the lower anterior wall of uterus.

A caesarean section was carried out in view of fetal distress. With delivery of a live male baby. Following complete removal of placenta and membranes, an intramural fibroid of approximate size $6 \times 5 \mathrm{~cm}$ was noted in the anterior uterine wall just $2 \mathrm{~cm}$ away from incision site (Figure 2 and 3). Myomectomy was performed and complete hemostasis was achieved. Histopathology later confirmed the diagnosis of myoma and the patient was discharged satisfactorily on day 3 of surgery without any significant intra op and post op complications.

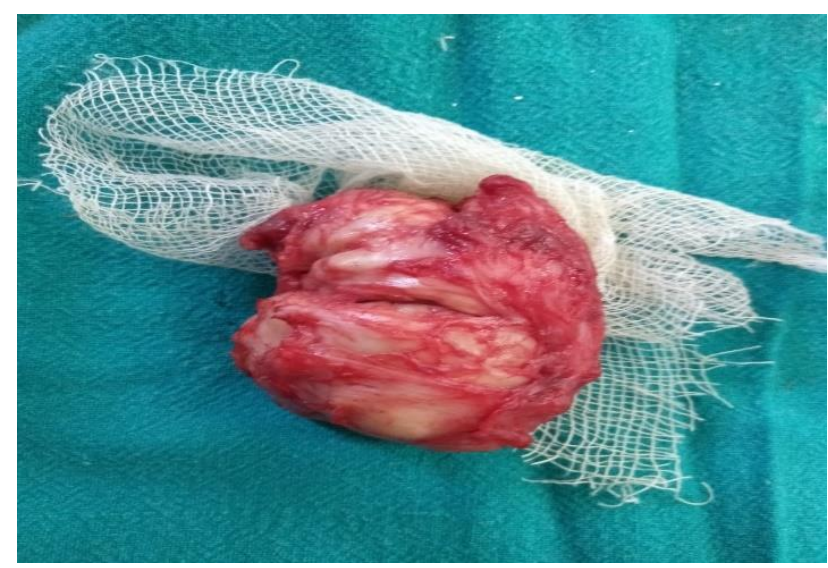

Figure 2: An intra mural fibroid $(10 \times 9 \mathrm{~cm})$ on the antero-fundal wall of uterus

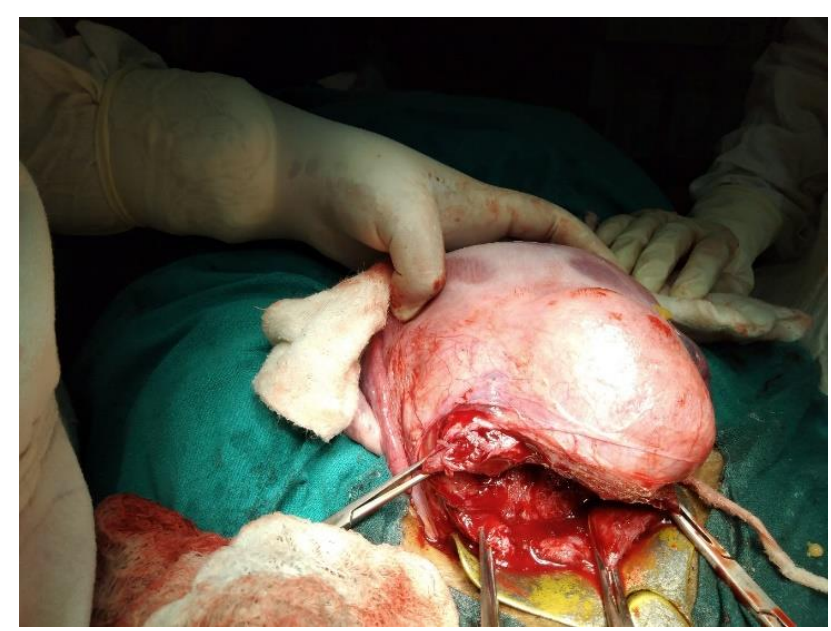

Figure 3: Intra mural fibroid $(5 \times 6 \mathrm{~cm})$ on the anterior uterine wall in the lower uterine segment.

\section{DISCUSSION}

Myomectomy during caesarean section has been discouraged by many surgeons due to fear of increased blood loss and post-operative morbidity and it is still a subject of debate whether to perform myomectomy during caesarean or not.

In these cases we have showed that myomectomy during cesarean section may not be as dangerous as it has been thought to be there has not been any significant increase in risk of hemorrhage, post-operative complications or prolonged hospital stay. ${ }^{1-3}$

Though intramural myomectomy should always be done with utmost caution and is advised to be avoided, in our cases with intramural fibroids or fibroids more than $5 \mathrm{~cm}$ in diameter, ${ }^{9,10}$ there was no significant difference in the intra operative and the post-operative outcome when compared to those with smaller fibroids or sub serosal or pedunculated myomas.

In patients with sub serosal or pedunculated fibroids especially in the lower uterine segment removal of myoma was safe and comparatively easier to perform.

With large myomas in lower segment of uterus, myomectomy may be necessary and there is no absolute contraindication to removal of such myoma.

Whereas small and single fibroids, if asymptomatic, need not be always removed.

With adequate experience and skills in cesarean myomectomy, use of vasopressin per operatively and higher dose oxytocin infusion, severe hemorrhage, which is the most dreaded complication, can be controlled to a large extent. ${ }^{16}$

\section{CONCLUSION}

It appears to be safe to perform myomectomy during cesarean section if surgeon is experienced and the size and location of myoma is considered.

It's better to remove large myomas in lower segment of uterus as they can lead to post-partum hemorrhage and sepsis but for small myomas in the fundal region, myomectomy may not always be indicated.

\section{Funding: No funding sources}

Conflict of interest: None declared

Ethical approval: The study was approved by the Institutional Ethics Committee

\section{REFERENCES}

1. Sparic R, Mirkovic L, Malvasi A, Tinelli A. Epidemiology of uterine myomas: A review. Int $\mathrm{J}$ Fertil Steril. 2016;9:424-35. 
2. Sparic R, Terzic M, Malvasi A, Tinelli A. Uterine fibroids: Clinical presentation and complications. Acta Chir Iugosl. 2014;61:41-8.

3. Cardozo ER, Clark AD, Banks NK, Henne MB, Stegmann BJ, Segars JH. The estimated annual cost of uterine leiomyomata in the United States. Am J Obstet Gynecol. 2012;206:211.e1-211

4. Coronado GD, Marshall LM, Schwartz SM. Complications in pregnancy, labor, and delivery with uterine leiomyomas: a population-based study. Obstet Gynecol. 2000;95:764-9.

5. Kaymak O, Ustunyurt E, Okyay RE. Myomectomy during cesarean section. Int J Gynaecol Obstet. 2005;89:90-93.

6. Sheiner E, Bashiri A, Levy A. Obstetric characteristics and perinatal outcome of pregnancies with uterine leiomyomas. J Reprod Med. 2004;49:182-6.

7. Davis JL, Ray-Mazumder S, Hobel CJ. Uterine leiomyomas in pregnancy: a prospective study. Obstet Gynecol. 1990;75:41-4.

8. Neiger R, Sonek JD, Croom CS. Pregnancy related changes in the size of uterine leiomyomas. J Reprod Med. 2006;51:671-4.
9. Kwawukume EY. Caesarean myomectomy. Afr J Reprod Health. 2002;6:38-43.

10. Shavell VI, Thakur M, Sawant A. Adverse obstetric outcomes associated with sonographically identified large uterine fibroids. Fertil Steril. 2012;97:107-10.

11. Sparic R, Nejkovic L, Mutavdzic D, Malvasi A, Tinelli A. Conservative surgical treatment of fibroids. Acta Chir Iugosl. 2014;61:11-66.

12. Baloniak B, Jasinskil O, Prews K. Slomko Z. Morphologic pattern of uterine myomas enucleated at cesarean section. Clinical Pol. 2002;73(4):255-9.

13. Kwawkume EY. Myomectomy during cesarean section. Int J Gyn Obs. 2003;76:183-4.

14. Ehigilgha AE, Ande AB, Ojobo SI. Myomectomy during cesarean section. Int J Gyn obs. 2001;75:21-5.

15. Cohellis L, Florio P, Stradella L, Lulia EP. Electrocautery of myomas during cesarean section, two cases reports. Eu J Obs Gyn Rep Biol. 2002.

16. Brown D, Myrie M. Cesarean myomectomy a safe procedure. West Ind Med J. 1997;46(2):450.

Cite this article as: Parveen S, Noor N, Madan I, Kulsoom U. A case series of caesarean myomectomy. Int J Reprod Contracept Obstet Gynecol 2021;10:3580-3. 